\title{
Study on the Application of Internet Technology in Individualized Teaching of College English
}

\author{
Jinjin $\mathrm{Gao}^{1, \mathrm{a}}$ \\ 1School of Humanities and Social Science of Xi'an Polytechnic University, Xi'an, Shaanxi, China \\ a18829218849@163.com \\ *Jinjin Gao
}

Keywords: Internet Technology, Individualized Teaching, College English Teaching.

\begin{abstract}
Internet technology and new curriculum reform have prompted the education to explore and innovate constantly, and gradually shaped a new form of "Internet Plus Education Models". Teaching methods and resources of college English have become richer because of the advantages of Internet. Teachers can make full use of Internet technology to realize individualized teaching mode, improving students' comprehensive strength in English learning and promoting development of college English teaching. Therefore, based on the individualized teaching, this paper mainly studies the application of Internet technology in College English teaching.
\end{abstract}

\section{互联网技术在大学英语个性化教学中的应用研究}

\author{
高瑾瑾1, a \\ 1西安工程大学人文社会科学学院, 西安, 陕西, 中国 \\ a18829218849@163.com \\ *高瑾瑾
}

关键词：互联网技术; 个性化教学; 大学英语教学

摘要. 随着互联网技术的革新和新课程改革的不断深入，促使教育领域也在不断地探索和创 新, 逐渐形成 “互联网+教育” 的新型教育形态。大学英语教学在互联网的指引下, 其教学方 式和资源也随之变得更加丰富, 教师可以充分利用互联网技术, 实现个性化的教学模式, 提 高学生英语学习的综合实力, 促使大学英语教学的良性发展。本文以个性化教学为出发点, 探索互联网技术在大学英语教学中的应用研究。

1. 引言

随着当代科技的发展和互联网时代的到来, 以及 “互联网+教育” 新教育形态的逐渐形成, 促使高校教育也在不断地进行模式和技术上的探索和创新。2007年教育部颁布《大学英语课 程教学要求》提出： “各高等学校应充分利用现代信息技术，采用基于计算机和课堂的英语 教学模式, 改进以教师为主的单一教学模式。新的教学模式应以现代技术, 特别是网络技术 为支撑，使英语的教与学可以在一定程度上不受时间和地点的限制, 朝着个性化和自主化的 方向发展。”

对当代大学生而言，兴趣和眼界的拓宽使其不再满足于传统教授式的小课堂而希冀于个 性化的大课堂, 互联网无疑为个性化教学提供了支持和使用价值。在互联网环境下, 学生获 
取知识的途径增多, 英语学习的自由度更大, 大学英语教学应科学的使用互联网技术和思维, 积极调动学生英语学习的积极性, 引导其个体性和多样化的特点发展, 从而提升大学生英语 学习的综合能力。

\section{2. 国内外研究和应用现状}

\section{1 国外互联网+教学的应用现状}

一些先进国家的互联网+教育模式发展比较成熟，应用和普及程度较高。主要体现在：(1) 课堂同步上线直播, 师生、生生实时互动; (2)课堂内容联网, 丰富新颖, 保证教学目的同时 增加趣味性和实用性; (3)文档共享, 题库自动生成, 学习效果在线测试、统计、跟踪和评价; (4)在线的课前预习、课后复习等。

其在网络课程设计上突破了时空限制，小教室变身大课堂，信息和资源使用最大化；同 时课堂内容和学生学习情况可随时查询追踪, 有利于及时了解学生的个性化和差异化, 从而 重视学生个体的学习特点和需求, 形成开放的、综合的、全民的、共享的、终身的网络教育 体系。

\section{2 国内互联网+教学的应用现状}

我国互联网+教育的发展受限于技术水平和教育思维的落后, 我国网络教育的应用始于 1994年，其模式是利用网络将课件或教学视频放在网上供学习者随时随地进行观看学习; 发 于2012年，我国首次发布《教育信息化十年发展规划》，推进建设教育资源公共服务平台和 教育管理公共服务平台; 进于 2018年，改革开放40周年，也是教育系统实施“奋进之笔”的进 取之年，纵深推进教育改革政策驱动和“互联网+”概念深化，以及MOOC、微课、翻转课堂、 微信、移动APP等多种微学习平台的应运而生, 使大学教育延伸至教室之外, 可供学生随时 随地进行学习。

但是，目前我国大学教育中互联网技术的使用处于初期阶段，仅仅是视频的录播、资料 的查询阶段, 并没有深化影响至课堂教学模式和日常学习中, 没有将课程内容实时与外界互 通互动。大学英语教育应该突破传统模式, 更注重于交流与讨论, 发展学生的辩证性思维, 以及拓展其专业领域知识。

\section{3 互联网技术}

互联网技术的本质是信息技术和通讯技术。从信息技术的角度看，当前的科技已经实现 了信息的数字化, 利于其存储和传播, 从而实现了信息的分享功能。从通讯技术的角度看, 互联网技术彻底改变了传统通讯方式, 使其更加高效便捷。

以教学资源分享为例, 其借助高度普及的智能终端如手机、电脑等, 通过移动互联网的 信息数字化技术，依托合适的教学平台或者移动APP，使得人们可以瞬间将海量信息分享到 教学平台, 便于学习者随时随地进行网络在线学习。

\section{4 个性化教学}

《国际教育百科全书》将“个性化教学”解释为: 一种以个体而非群体为基础的教育形式, 与诸如演讲或小组教学等以群体为基础的教学方法相比, 在学习步子和学习时间方面, 几乎 一切个性化教学都允许学生有更大的灵活性, 教学适应学生个人需要的程度随所采取的特殊 方法而变化。

由此可见, 个性化教学是针对传统的将学生一概而论的教育弊端而提出来的, 是益于学 生个性发展的新型教育模式。其强调学生的个体差异, 注重学生的个性需求与发展潜力, 确 立学生在教育中的基本地位, 完全符合新课改下“以人为本”的教育理念。个性化教学能充分 
调动学生英语学习的积极性和主动性, 满足不同学生的学习需求, 从而实现“因材施教”的教 学目的。

\section{3. 互联网技术在大学英语个性化教学中的应用}

互联网技术的应用与普及对大学英语个性化教学的实施提供极大的帮助，“互联网+”环 境下个性化教学为学生提供了丰富的知识体系, 促使学生都能找到适合自己且感兴趣的教学 内容, 利于提升学生的学习兴趣和动力, 并提高其英语的综合运用能力。以下具体结合教学 实践探讨互联网技术在大学英语个性化教学中的应用。

\section{1 制定个性化的教学模式}

“互联网+教育”在很大程度上革新了高校人才的培养方式。高等教育应更加注重开放性 和个性化, 注重学生个性化的培养和特长的发挥, 从而实现现代社会对人才培养的多样性和 个性化的需求。大学英语个性化教学应以学生为中心，应该根据学生个体的个体差异性如专 业需求或兴趣、学生对知识的掌握程度或英语水平等, 有针对性地引导其学习英语。

在个性化教学过程中，教师可将预习材料和知识点等以微课视频或音频等形式分发学生 进行自主学习, 课堂上实施以学生为主体的教学活动, 教师引导鼓励学生进行小组讨论, 促 进学生对专业知识的内化吸收。课后教师也可以充分利用网络技术跟踪学生的学习动态, 通 过微信、QQ、私信等方式与学生进行及时的互动交流, 掌握学生的学习情况, 并根据数据反 馈和学生的意见对教学的内容和方式方法进行适当调整。

\section{2 构建个性化的教学环境}

个性化教学模式的实施要求构建个性化的教学环境。著名教育家李秉德教授认为教学环 境对教学模式、教学活动的顺利组织实施有着重要的影响。大学英语教学应充分利用互联网 技术构建网络自主性学习和课堂教学相结合的个性化教学环境。此外, 教师在教学过程中, 也应注意因材施教，注重学生的个性化发展。

具体来说, 在课堂上教师可以根据学生的个性特点改变大学英语的教学模式, 并借助于 网络媒体资源, 提供给学生感兴趣的教学内容, 使得英语教学得到有效的扩展和延伸, 丰富 学生的知识面, 提高学生英语学习综合能力。与此同时, 教师应帮助学生构建线上线下、随 时随地的自主性的网络学习平台, 优化传统的单一的教学模式, 从而全面实现大学英语的个 性化教学。

\section{3 制定个性化的评价模式}

现代大学生在培养过程中, 要树立 “以人为本” 的教育理念, 在尊重个体差异性的同时 应该制定个性化的评价模式，对学生进行更科学更准确的评价。

大学英语个性化的教学评价旨在检验教师教学和学生学习过程, 发现教学中存在的问题, 及时做到调整和改善, 以此有效促进英语教学环节的顺利实施。个性化的评价模式在注重学 生的个体差异性, 学习环境的复杂性和多样性等情况下, 应充分利用互联网技术, 监测学生 的学习状态, 并根据收集到的数据进行学生学习状态和自主学习的数据分析, 从而对学生的 学习提出具体且针对性的意见, 进一步提高学生的英语学习能力。

此外, 教学评价应包括教师评价、学生自评和学生互评三个部分, 评价过程应注重学生 主体性和个体差异性, 尤其对于基础较差的学生应进行积极指导, 对这类学生的学习过程和 作业情况应适当指正, 多肯定学生的改变和进步, 真正实现教学评价的多元化、多样性和个 性化。 


\section{4. 结束语}

互联网环境下大学英语个性化教学是教育改革下的一种全新的教学形式。以学生的个性 化差异为出发点, 通过课前、课中和课后三个环节, 以互联网技术为支撑, 形成了师生线上 线下双向及时的互动, 提高学生学习的积极性和主动性, 从而极大提高了教学效率和教学效 果。

互联网技术下的个性化教学对我国教育事业的发展也有极大的促进作用，其不仅利于教 师教授模式的改变与革新，也促进了学生个性化的凸显。在大学英语教学中，应充分利用网 络资源扩大优秀课程影响力和传播范围, 为学生提供多元化的英语学习渠道, 并制定合适、 具体、有针对性的教学方式, 做到因材施教, 从而提高我国大学生的英语综合应用能力, 进 而促使大学英语教学的良性发展。

此外, 基于不同学生的个体差异性, 大学的教育教学在注重学生个性和特长发展的同时, 更要凸显大学人才培养的个性化和定制化。而个性化人才培养方案的实现，一定要借助于互 联网信息技术，从英语的个性化教学环节向外延伸，对人才培养目标、课程体系、考核评价 等多方面进行调整改善, 为每位大学生的个性化发展提供需求。

\section{References}

[1] Cai Weina, On Personalized College English Teaching, Innovation Education, vol.10, 2014.

[2] Zhao Shouxia, Research on the Strategy of Individualized Teaching in College English Under the Multimedia Network Environment, English Teachers, vol.18, pp. 621-000, 2018.

[3] Wang Chunxiu and Lan Ying, A Study on the Application of Personalized Teaching in English Major Teaching, Language Arts and Sports Studies, vol. 4, pp. 110-167, 2018.

[4] Deng Guping, Research on the Bottleneck and Breakthrough Mechanism of Personalized Teaching under the Internet+ Background, Vocational Education Newsletter, vol.4, pp. 410-124, 2019.

[5] Zhao Xiangze, The Application and Influence of Mobile Learning in English Teaching in Higher Vocational Colleges, HEILONGJIANG SCIENCE, vol.8, pp. 0076-02, 2017.

[6] Chu Changlin and Mo Cancan, Innovation Development and Future Trend of Higher Education under the Background Internet Plus, Chongqing Higher Education Research, vol.5, pp. 121-127, 2017. 